\title{
Stewardship as an Organizational Response: Understanding the Interaction of Institutional and Task Environments and Organizational Contexts on Fund Raising in Professional Schools and Colleges at the University of Michigan
}

Received (in revised form): May 27, 2003

\section{T. Gregory Barrett}

is an assistant professor of Higher Education at the University of Arkansas at Little Rock. He has a Ph.D. in Higher Education from the School of Education, University of Michigan at Ann Arbor. He has over ten years' experience in nonprofit management and fund raising with Georgia Special Olympics, the American Cancer Society, and Spelman College.

\begin{abstract}
Stewardship, defined in terms of shared beliefs, social structure, and organizational routines, was explored using a comparative case study approach to determine how conditions in the institutional and task environments and internal organizational characteristics influence the nature of the stewardship process in five professional schools at the University of Michigan. Data were collected through interviews,
\end{abstract}

Author's Contact Address:

T. Gregory Barrett

The University of Arkansas at Little Rock

School of Education, Department of Educational Leadership 2801 S. University Ave.

Little Rock, AR 72204-1099, USA

Tel: +15015693016

Fax: +1 5015693547

Email: tgbarrett@ualr.edu documents, and archival records. Informants in each case study unit included the dean of the school, as well as senior development administrators, major gift officers, and development staff. As theorized, the analysis revealed that resource dependence, uncertainty regarding donor behavior, and interconnectedness are the major influences on stewardship from the task environment. Pressures for legitimacy, efficiency, external legal coercion, and the voluntary diffusion of norms were influential on stewardship from the institutional environment. Organizational factors including centralization, configuration, design and management of tasks, interactions, political process, reputation, and competition were also 
influential on stewardship. Unanticipated factors that emerged from the data suggesting their influence on stewardship included internal pressures from the institutional environment, diversification and stockpiling from the task environment, and institutional commitment to fund raising through staff and monetary resources from the organizational context.

\section{Keywords:}

stewardship, higher education fund raising, public higher education fund raising, organizational theory in fund raising, task environment, institutional environment, organizational characteristics, major donors

\section{Introduction}

Considered a key to ensuring future gifts, stewardship is a component of the fundraising process which is conducted for major donors to colleges and universities. The process begins at the time a major donor pledges or conveys a gift. ${ }^{1}$

Stewardship is defined in this study as sets of organizational routines, shared beliefs, and social structures which comprise a cyclical process that completes itself when a major donor makes his or her next gift. ${ }^{2}$ The primary research question for this qualitative study is: what environmental conditions and organizational characteristics influence the nature of the stewardship process for major gift donors in professional schools and colleges at the University of Michigan?

\section{Literature Review}

This study views the stewardship process as an organizational response to the institutional and task environments with which it interacts and to the organizational characteristics with which it is faced. Institutional environments are composed of regulative, normative, and cognitive mechanisms that impose pressure on the organization to achieve legitimacy by conforming to those pressures. ${ }^{3}$ Task environments relate to the goals of the organization exemplified by exchanges with the environment designed to secure "sources of inputs, markets for outputs," and to outdo its competitors. ${ }^{4}$ Organizational characteristics are composed of the structures, processes, and position of the organization. 5 Scott identified three carriers or repositories within which organizations are embedded. ${ }^{6}$ These carriers are cultures (shared beliefs), social structures, and routines. An organization's shared beliefs, social structures, and organizational routines store the knowledge or "procedural memory" that guides who is to respond to an environmental stimulus, what is to be done, when it is to be done, where it will be done, and how it will be done. ${ }^{7}$ Because these responses comprise an organizational process and stewardship is by definition a process, this study defines the stewardship process in terms of these three carriers.

\section{The stewardship process as shared beliefs, social structure and organizational routines}

Shared beliefs and values are an integral part of an organization's cultural identity, and serve as a necessary prerequisite to collective functioning. Langfield-Smith notes that a culture has a language, a relationship with its environment and a history, all of which may influence the structure and content of its social typifications. ${ }^{8}$ This study, therefore, I operationalized shared beliefs as social typifications composed of: shared 
understandings of the stewardship process, common socialization processes for new members to the organization, a common "language" revolving around development and stewardship, and a history of the stewardship process in the organization.

Social structure has been described as "the patterned or regularized aspects of the relationships existing among participants in an organization."9 Social structure was studied in terms of Gross, Mason, and McEachern's standardized system for empirical role analysis using position and role to examine the social structure of the stewardship process within four professional schools and one professional college at the University of Michigan. ${ }^{10}$

Nelson and Winter conceptualize organizational routines as being "all regular and predictable behavioral patterns of the [organization]." ${ }^{\prime 1}$ Nelson and Winter also distinguish three classes of routines. Routines that govern short-run behavior in which factors of production (budget, number of development staff, etc.) are not easily augmented are called operating characteristics. This class of routines relates to what the organization does at any given point in time. Routines that determine period-by-period augmentation or diminution of the firm's capital stock (those factors of production that are fixed in the short run) are the second class of routines. Finally, routines that serve to modify over time various aspects of an organization's operating characteristics represent the third class of routines. Nelson and Winter assert that "from time to time some people within the firm may engage in scrutiny of what the firm is doing and why it is doing it, with the thought of revision or even radical change."12 These three classes of organizational routines-short term, periodby-period, and modifiers of operating characteristics-were used as the lens to examine the stewardship process as sets of organizational routines.

\section{Environmental conditions}

Based on empirical findings and theoretical propositions, it is assumed that resource dependence theory and institutional theory are appropriate theoretical lenses by which to view Research I University fund-raising organizations. ${ }^{13}$ Then, following Scott, it is assumed that there are two aspects of environments that confront organizations. The first aspect is the task environment, which reflects the more materialistic and resource-based elements of the environment. Because of this focus on resources, task environments may be explained in large measure by resource dependence theory. ${ }^{14}$ The second aspect of the environment that faces organizations is the institutional environment. The focus of the institutional environment is on the more cultural or symbolic influences that impact an organization. ${ }^{15}$ Thus, institutional theory best explains the institutional environment.

Four dimensions define task environments. These dimensions are resources, information, complexity, and enactment. The resource dimension is concerned with dependence and munificence. ${ }^{16}$ The information dimension is concerned with uncertainty and coordination. ${ }^{17}$ The complexity dimension is concerned with stability and threat. ${ }^{18}$ And the enactment dimension is concerned with how the organization modifies its environment. ${ }^{19}$

Oliver identified five factors that define institutional environments, four of which, 
cause, constituents, content, and control, are pertinent to this study. ${ }^{20}$ Each of the four factors-factors which Oliver termed antecedents of strategic responses-is influenced by two dimensions. Cause looks at why the organization is being pressured to conform through the lens of the organization's need for legitimacy and efficiency. Constituents examines who is exerting the pressures in terms of the multiplicity of constituent demands being placed on the organization and the level of dependence that the organization has on its institutional constituents. Content views the environment in terms of the requirements to which the organization is being pressured to conform. The dimensions that influence the organization in this factor are how consistent the requirements are with the institution's goals and what type of discretionary constraints are being imposed on the organization. Control examines how pressures are being exerted in terms of legal coercion or voluntary diffusion of norms. ${ }^{21}$

\section{Organizational factors}

The study assumes that organizational factors help define the nature of the organization. Miles identified four structural dimensions of an organization. ${ }^{22}$ These structural dimensions are centralization, formalization, complexity, and configuration. ${ }^{23}$ Scott identified the process dimensions embedded in the design and management of core technologies and tasks while Homans identified the collective activities and interactions of individuals, and Pfeffer and Salancik discussed the political process involved in the process dimension. ${ }^{24}$ Rosevear identified organizational reputation, competition, interdependence, and technological capacity as determinants of organizational position. $^{25}$

\section{Conceptual framework}

The conceptual framework was derived from a review of the relevant literature (see Figure 1). It suggests several dimensions that influence the nature of stewardship in colleges and universities. Essentially, these dimensions of influence relate to organizational theories that would seem to predict how this function evolves in American Research I Universities and describe the nature of the processes, relationships, and environmental interactions that embody the process called stewardship.

Following Scott's conceptualization, characteristics of organizational environments can be divided into task and institutional conditions. ${ }^{26}$ Depending on the organization's reaction to these forces, it may choose some sort of strategically adaptive response.

Organizational factors such as its structure, process, and position may also influence the nature of an organization's response. As indicated by the two-way directional arrows, the environment and organization have the capacity to influence one another. This environmentorganization interaction provides at least a partial explanation for the type of organizational response that the organization chooses. And these response strategies are explained by the critical contingencies identified by Oliver and the amount of resources-both financial and human resource-that are committed to the stewardship process. ${ }^{27}$ The feedback loop from stewardship back to the organization's environment is in keeping 


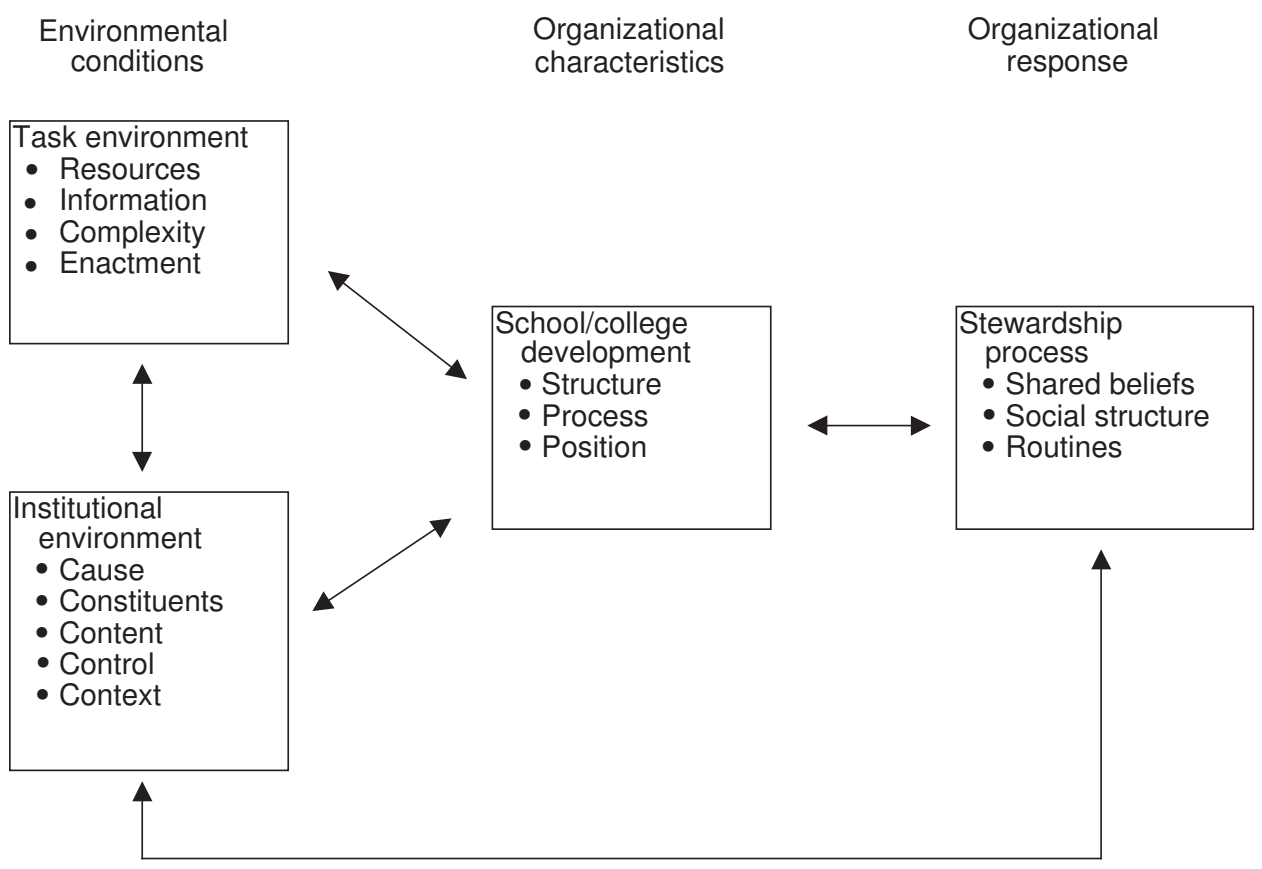

Figure 1: Conceptual framework: Determinants of the strategic organizational response called stewardship

with Cook and Lasher's concept of stewardship and the college fund-raising process as a whole being cyclical in nature.

\section{Method}

This study employed a comparative case study methodology within a single institution to compare the varying nature of stewardship between and within five professional schools and colleges. Three sources of evidence were gathered for the case study data analysis-documents, archival records, and interviews. ${ }^{29}$ Primary data sources were interviews with deans and development professionals at five professional schools and colleges at the University of Michigan and documentary evidence to establish the context within each academic unit.

The tape-recorded responses of the 31 informants were transcribed verbatim to provide the rich description of direct quotations of these administrators and fund raisers. The transcriptions were then coded to conform to the seven independent variables and three dimensions of the dependent variable of stewardship in the conceptual framework.

\section{Limitations}

Due to the exploratory nature of this study and the fact that only five professional schools or colleges were studied, the results of the study may not be generalizable to other public Research I Universities. Another possible limitation is the fact that the author worked on an earlier comparative study of the stewardship function at this university. This experience, however, may also have 
benefited the present study by his having a better understanding of the stewardship function at this university at an earlier time in the evolution of this process.

\section{Findings}

\section{Definitions of stewardship}

\section{Shared beliefs}

The informants in each of the schools and the college in the study had common sets of shared beliefs that collectively contributed to the group understanding of what constitutes stewardship in their respective development operations. These common understandings serve as the cultural knowledge that determines how the stewardship process will be elaborated. The assistant dean for development and alumni relations at the Law School expressed that common understanding well:

Stewardship is the ongoing relationship with the donor: to make him or her aware of how his or her gift is being used and to make them feel comfortable with the fact that you are using that gift well. To acknowledge it, to thank them for it, to go on from there, whether or not you are going to have a longer term relationship with the donor-which you hope you do. But the stewardship comes before that happens.

Each of the five case organizations uses "in-house" socialization processes. Though socialization differs somewhat from organization to organization, the basic process is the same-immersing new staff in the unique disciplinary culture that composes the professional school or college. One difference is that the most successful organizations appear to hire development staff members who have been successful in other fund-raising units at the University of Michigan rather than going outside the university to hire staff.

The vocabulary of the language of fund raising that was identified in the units varied somewhat across the professional schools. Though a few key words were identified by the majority of the case study organizations, most of the words were not. The words that were identified by only one or a few units appear to be indicative of the priority area of fund raising on which the specific case study organization was focusing. For example, the Law School identified the term "prospect pool." This shows they are emphasizing enlarging the number of major donor prospects for the school. The Business School identified "major gifts," "targeting alumni," "managing expectations," "pooled incomes," and "bequests." These words are indicative of the school's emphasis on securing major gifts as the result of strong long-term relationships. The College of Engineering identified "coordination," "personal motivation," "advancement," and "nuance." These words are indicative of the approach taken by the development administrators in the college in which great pains are taken to understand what motivates their major donors and prospects and then to determine what mutual interests will advance both the college and the long-term relationship between the major donor and the college. The School of Music identified "annuity," "planned gift," "contract," "pledges," "commitments," "capacity," "designated gifts," "expendable gifts," "restricted gifts," and "high maintenance donors." These words are indicative of a school that 
is working hard to develop its major donor base. In sum, these examples lend credence to the assertion that language is part of the cultural knowledge of the organization.

Each of the schools and the college in the study also has a history of stewardship, however brief, that their administrators, development officers, and development support staff can identify. The histories serve as an integral part of the cultural knowledge of these organizations.

\section{Social structure}

Social structure also plays a role in the elaboration of the stewardship process in each of the schools and the college involved in the study. Position was examined both for the ranking managing development officer in each unit and for the person or persons charged with the stewardship function in each unit. The position of the managing development officers, as reflected by their titles, seems to make little difference in the influence they are able to exert on the stewardship process. Length of service and fund-raising success seem to be more important. The position of the person responsible for the stewardship function does seem to be indicative of the priority the school or college places on stewardship, however. Similar to the analysis of position, the roles described by the persons responsible for the stewardship function were indicative of the priority their organization places on stewardship.

\section{Organizational routines}

Organizational routines were also found to be important in the stewardship process. Short-term routines include such things as gift acknowledgements, thank you letters from scholarship recipients to their benefactors, progress reports from program directors and holders of endowed professorships to their benefactors, annual endowment reports and annual events such as reunion activities and scholarship events. Many of these routines have been centralized to take advantage of economies of scale.

The period-by-period routines comprise much of what might be termed the "interpersonal aspects of stewardship." They include such things as staffing decisions, one-time campaign events, and special one-of-a-kind recognition events. They also include the very personalized stewardship programs which are created for principal and major donors as part of the cultivation process in anticipation of securing future major gifts. All of the schools and the college examined manifested period-by-period routines by either recently hiring new staff, a portion of whose job is dedicated at least in part to the stewardship process, or by assigning existing staff to specific stewardship responsibilities.

Modifiers of operating characteristics are activities in which internal actors engage to review operating procedures and characteristics with the intent of revising or even radically changing those characteristics. All of the case study organizations have recently undergone or are currently going through a process of self-evaluation. These self-evaluations have uniformly increased the priority and the elaboration of the stewardship process within these organizations.

\section{Task environment}

\section{Resources}

The task environment plays an integral role in explaining both the need for, and 
how formalized the stewardship process becomes in the professional schools and college in the study. For example, all of the schools and the college studied were dependent on resources from private support to some extent for their survival. Two of the schools and the college have external sources of revenue-Dentistry has dental clinics, Business has executive education programs, and Engineering has research grants and contracts-which cushion their need for private support.

The professional schools with more successful fund raising units also have environments that are more munificent than the less successful units. Part of this munificence is explained by the higher incomes of alumni from the Schools of Business and Law and the College of Engineering and part of the munificence is explained by all three of these organizations having substantial alternative sources of revenue.

\section{Information}

Information is another aspect of the task environment that is important to stewardship. All of the case study organizations minimize uncertainty by utilizing the wealth of informational resources made available to them through Central Development. These research tools can identify prospective major donors, but what they cannot tell is whether a prospect has either the inclination to make a gift or current access to funds given the existing economic conditions.

Coordination of information follows the accepted norms of each case study organization. Individuals with the closest personal relationships to the prospects prepare briefing documents, plans are coordinated by committee or in consultation with unit administrators, and actors mutually adjust based on potential gift size and on how important the individual prospect is to the organization.

\section{Complexity}

Environmental complexity determines an organization's stability and how interconnected it must be with its external actors in order to survive. All of the case study organizations sought to maximize environmental stability by minimizing turnover among their major donors and by maximizing the predictability of their donors' behavior. Perceptions of stability varied by size of the units. The smaller fund-raising units, Dentistry and Music, perceived their environments as being unstable. The larger, more successful, fund-raising units perceived their environments as being stable. These larger units have more staff available to provide stewardship for their major donors. Income levels also have a great deal to do with environmental stability so the School of Dentistry's environment should be more stable than it perceives.

A primary way these professional schools and the college achieve stability is by embedding their major donors and prospects within their organizations through committee structures. Size again plays a major role in the success these case study organizations have in achieving this interconnectedness. Schools and the college with larger staff have more people to coordinate committees and special events that help embed their donors and prospects in their organizations. For example, the assistant dean for development and alumni relations at the Business School described the process of trying to develop future points of mutual interest and activity that might generate another point of financial support: 
It involves attending funerals of family members of donors, attending weddings, sending congratulatory notes, advising parents and grandparents about their daughter's, son's, grandchildren's college plans or their career plans. It's the whole spectrum of what a relationship represents. As you get deeper in these relationships, you become a friend, a confidante, and an advisor and you have to be prepared to spend time to foster that aspect of the relationship.

Smaller units with smaller staffs are forced to place primary priority on securing major gifts in hopes that someday they will achieve better interconnectedness with their donors.

\section{Enactment}

Each of the schools and the college that was studied is attempting to socially construct or enact its individual environment through the upcoming campaign. Because enactment is subject to multiple interpretations it means different things to the different schools and the college. ${ }^{30}$ Regardless of specific interpretation, they are all trying to find ways to raise more money to support their organizations.

\section{Institutional environment}

\section{Cause}

Cause looks at why an organization is being pressured to conform to institutional rules or expectations. ${ }^{31}$ Each case study organization seeks to legitimate itself with its constituents. The Law School does so by retaining its "sense of ourselves as a public institution" even as it becomes increasingly privatized. The
School of Dentistry does so through "the indigent patient care that our students provide all across the State of Michigan." The Business School does so by building honest relationships with its major donors rather than finding itself doing "things that are really not in your best interest or the donor's best interest in terms of the long-term relationship between you, the donor, and the organization." The College of Engineering does so by having a "donor-first mindset" that treats "resources not just in [terms of] hard dollars, but in [terms of] what the hard dollars do to add value across the whole spectrum." The School of Music does so through performances of its students and faculty. According to the Dean, "depending upon the level and significance of the donor, we respond and we love to do it. That's what we do for a living."

Neither the School of Dentistry nor the School of Music expressed any external pressure to conform to efficiency or economic fitness. However, the Law School responds to expectations of its alumni to implement effective fund-raising practices the alumni have seen practiced in other institutions to which they have allegiances. The Business School responds to donor pressures for annual endowment reports. The College of Engineering rationalizes its large budgetary expenditures on capital improvements based on the high quality campus that these expenditures provide.

\section{Constituents}

The constituents variable explains who is exerting institutional pressures on the organization. ${ }^{32}$ This study limits the constituents to the donors and prospective donors to the case study organizations. All 
of the professional schools and the college involved in this study expressed having received a multiplicity of constituent demands. Because all of these schools and the college are dependent to some degree on their donors for their existence, each of them attempts to conform to those demands but without relinquishing their autonomy.

\section{Content}

Content looks at the norms or requirements to which the organization is being pressured to conform. ${ }^{33}$ All of the professional schools and the college agreed that they were not being pressured to conform to organizational goals that were not consistent with their own goals because Central Development does not have a formalized set of standards for stewardship. The only discretionary constraint identified by all of the professional schools was the universitywide prospect coordinating system. Other discretionary constraints identified were the cumulative giving recognition programs, centralized endowment reports, and standardized gift agreements. The College of Engineering is so concerned by the centralized endowment reports that it is negotiating to produce its own reports or to have key information they already provide to their donors incorporated into the centralized reports.

\section{Control}

Control views how or by what means institutional pressures are being exerted. ${ }^{34}$ The case study organizations identified three levels of legal coercion: the federal government, the state government, and Central Development. The Central Development level of legal coercion was added to Oliver's predictive dimensions because it emerged from the study and it was not included in Oliver's framework. Federal coercion exists through IRS regulations regarding services exchanged for a gift, guidelines for the establishment of charitable remainder trusts, and legal technicalities involved in gift agreements. State government coerces these organizations through the "open public reporting" act requiring the Board of Regents to publish a monthly report of gifts received by the university and by requiring that all endowed gifts be managed through a single university-wide endowment fund. Central Development has imposed legal coercion through its centralized endowment reports.

Stewardship at this Research I University has been implemented almost entirely by the voluntary diffusion of norms. This is so because neither Central Development nor the Council for the Advancement and Support of Education (CASE) has formalized standards for stewardship. Thus all the improvements made in the stewardship process come from benchmarking best practices in other professional schools and the college at the University of Michigan or at peer professional schools across the country.

\section{Organizational factors}

\section{Structure}

The structural dimensions of the case study organizations include centralization, formalization, complexity, and configuration. ${ }^{35}$ All of the development officers interviewed at the professional schools and the college agree that the stewardship process is decentralized. However, there are a number of centralized support services for the stewardship process that highlight the two distinct elements of the stewardship 
process-the mechanical elements which lend themselves to centralized processes, and the interpersonal elements which can only be effectuated through close relationships between an agent of the school and the donor or prospect.

Formalization of goals for stewardship is generally found only in performance plans for development officers or development support staff who have direct responsibility for stewardship. ${ }^{36}$ Only in one case has a major gift officer voluntarily written goals for stewardship into her performance plan.

Because the five case study organizations operate in a mediating technology with multiple donors distributed across space and time, and because each development office is responsible for widely divergent responsibilities, they each exhibit different levels of complexity. ${ }^{37}$ For example, one of the largest units, the Business School, has the simplest functional structure with only two functions, while one of the smallest units, the School of Music, divides its functions into 13 parts.

Configuration relates to the division of labor, organizational hierarchy, and managerial span of control within the professional school and college development offices. ${ }^{38}$ There is great variation across cases in how differentiated the division of labor is, how tall or flat the organizational hierarchy is, and how wide the managerial span of control is. These differences appear to arise from differences in staff size and in the functional responsibilities assigned to each of the various development offices.

\section{Process}

The process dimensions of the case study organizations include the design and management of technologies/tasks, activities, interactions, and political process. The design and management of tasks is socially constructed based on a combination of the management style of the dean; the management direction given by the assistant dean for development or the director of development; what is technologically possible within the organization; and what is socially acceptable to the administrators, development officers, and development support staff. ${ }^{39}$

Activities are the elements of behavior in which individual actors engage. ${ }^{40}$ As would be expected, the stewardship-related activities of the managing administrator in each of the development units are all quite similar.

Interactions between development staff and major donors to their professional school or college are units of activity stimulated by some other unit of activitythe donor making a gift to the school or college. The development staff members conduct stewardship-related activities in hopes that their interactions with donors will eventuate additional interactions in the form of additional major gifts.

Political process relates to the manner in which the organization deals with both internal and external conflict. Each of the areas of potential or actual conflict which were identified by informants in the case study organizations are traceable to issues of concentration (the extent to which power and authority in the environment are widely dispersed), munificence (the availability of scarce resources), or interconnectedness (the number and pattern of linkages or connections among organizations) which Pfeffer and Salancik assert determine the degree of conflict and interdependence present in a social system. ${ }^{41}$ 


\section{Position}

Position dimensions in the case study

organizations include reputation, competition, interdependence, and technological capacity. The study inquired about the influence of two aspects of the reputation of each school or college-the academic reputation and the fund-raising reputation. Each of the schools and the college agreed that the academic reputation was critical to the gift-giving decisions of their major donors. However, individual interpretation of what comprises "fund-raising reputation" by each of the key informants appears to be the key as to whether or not they perceive it to influence donor behavior.

Competition was viewed through two lenses-between schools and colleges at the University of Michigan and with peer professional schools across the country. Competition between schools and colleges at the University of Michigan arises because a large percentage of alumni of the university have multiple affiliations to it (e.g., undergraduate and graduate degrees from different schools). For this reason, Central Development created the centralized prospect coordinating system which is designed to coordinate cultivation and solicitation activities for the units with whom a donor may have multiple affiliations and to maximize the utility of a prospective gift to the university as a whole rather than to a single academic unit. Competition between peer professional schools for top faculty is also an issue for these schools.

Interdependence was narrowly defined in this study as being between the organization and its donors. Because of this narrow definition, the only real case of interdependence that emerged from the study was that between dentists and the
School of Dentistry because of the state's requirement for continuing dental education.

Technological capacity was defined as the capacity to secure and utilize fundraising technologies. Each of the professional schools and the college investigated in this study have all the computer technology they need to access the state-of-the-art research and database technology that is offered through Central Development. Therefore, technological capacity is not an issue for these case study organizations. They all have high capacity.

In summarizing the study's view of the stewardship process as an organizational response, one concludes that the nature of the stewardship process is manifested in both routinized sets of processes at Central Development and in the academic units as well as in personalized programs of stewardship conducted by individuals who have close interpersonal relationships with the donors. The extent of stewardship is that it is ubiquitous across all the case study organizations but it is much more fully elaborated in the schools and the college that have more major donors, more development staff, and more funding to make the process work.

\section{Emerging issues and other findings}

In addition to the basic findings directly related to the conceptual framework, several other issues emerged that are interesting for fund raisers and scholars of fund raising. Two of the emerging issues relate to the task environment, two relate to the institutional environment, three to organizational characteristics, and two are general observations. (For a complete explanation of the environmental and organizational dimensions and the 
Table 1: Explanation of revised environmental and organizational dimensions and variables of the conceptual framework

\begin{tabular}{lll}
\hline Conceptual dimensions & Variables & Definitions \\
\hline
\end{tabular}

Environmental conditions

Task environment

- Resources

- Information

- Complexity

- Enactment

Institutional environment

- Cause

- Constituents

- Content

- Control
- Dependence

- Munificence

- Diversification

- Stockpiling

- Uncertainty

- Coordination

- Stability

- Interconnectedness

- Enactment

- Legitimacy

- Efficiency or economic fitness

- Multiplicity of constituent demands

- Consistency with organizational goals

- Discretionary constraints imposed on organization

- Legal coercion
- Extent to which the organization is dependent on donors for the resources essential for its survival

- Extent to which donors with sufficient resources to make major gift contributions are available to the organization

- Extent to which the organization has alternative external sources of revenue

- Extent to which the organization sets aside critical slack resources to buffer uncertainties in the future

- Extent to which the organization feels uncertain about its ability to predict a donor's behavior in advance

- Extent to which the organization coordinates flow of information accurately to decision makers

- Extent to which the organization perceives the external environment as stable

- Extent to which the organization is interconnected with environmental actors that have power to influence it

- Extent to which the organization constructs, rearranges, singles out, and demolishes features of its environment

- Extent to which the pressure to conform is legitimacy

- Extent to which the pressure to conform is efficiency or economic fitness

- Number and types of demands being made on the organization

- Extent to which the organization is being pressured to conform to institutional goals opposed to its own

- Extent to which the demands being made on an organization constrain its discretion

- Extent to which the organization is being legally coerced to conform

- Intraorganizational - Extent to which the focal organization is being coercion

- Voluntary diffusion of norms coerced to conform by another organization above it in the larger university hierarchy

- Extent to which the organization voluntarily diffuses organizational norms 
Table 1: Explanation of revised environmental and organizational dimensions and variables of the conceptual framework-Continued

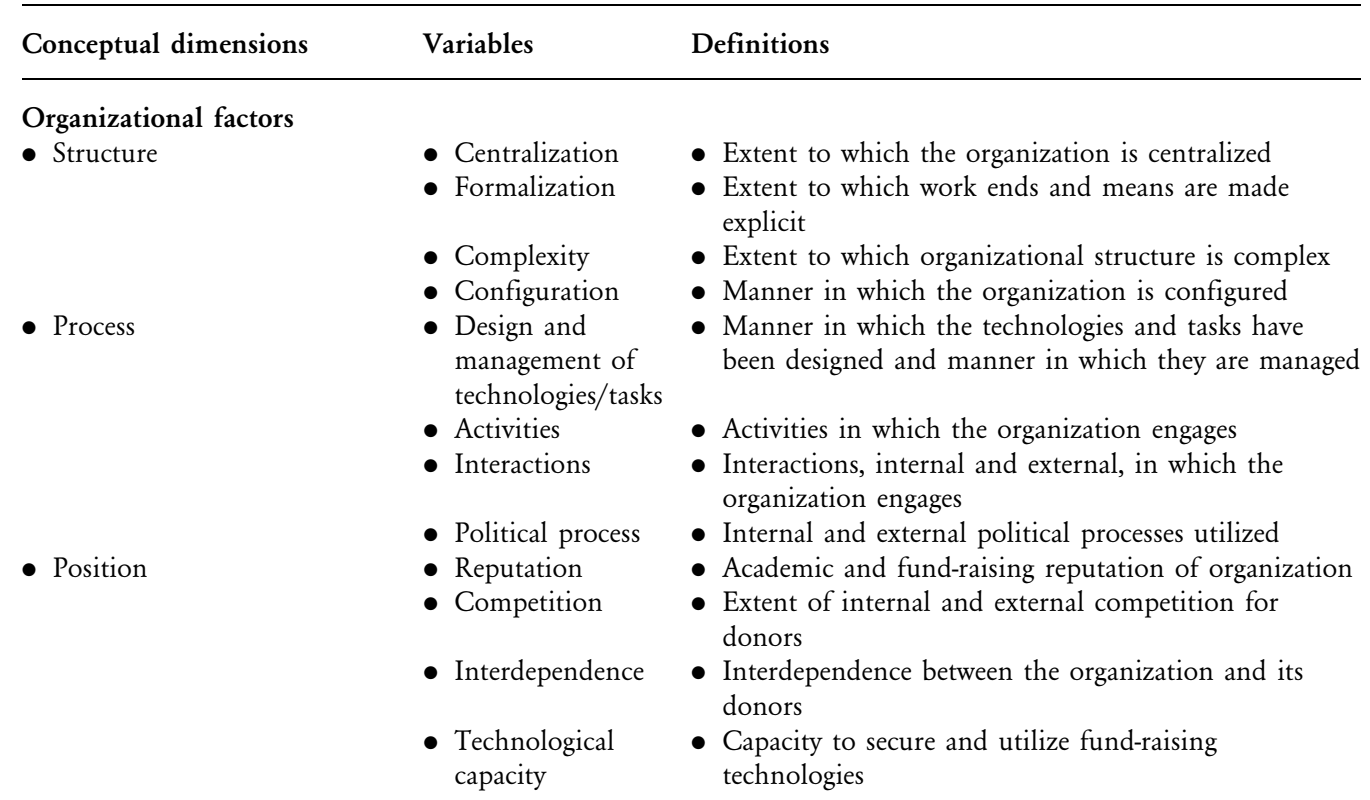

variables of the conceptual framework, please see Table 1.)

The first emerging issue in the task environment relates to munificence. This issue is a changed culture of philanthropy in which younger people in their late twenties, thirties, and forties have the capacity to make major gifts. This calls for a new approach to fund raising that will position colleges and universities to better meet the interests and needs of a younger cohort of donors. The second emerging issue in the task environment relates to enactment. This issue relates to the vast disparity in resources between the "small" fund-raising units and the "large" fundraising units. This disparity in resources means the small units are unable to devote the time and energy needed to implement effective stewardship programs for their major donors. They are too busy using their limited resources trying to secure new gifts.

Emerging issues in the institutional environment relate to legitimacy and efficiency or economic fitness. The emerging issue related to legitimacy is the sophistication of today's major donors and the fact that they have multiple affiliations with other elite universities where they are exposed to the most effective fund-raising strategies and processes available. These prospects apply pressure to this university's professional schools to emulate these successful practices. The emerging issue related to efficiency or economic fitness is the prospect management function that has been taken 
on by major gift officers at Central Development for the smaller academic units. The rationale is efficiency because the small units do not have enough prospects in geographic areas around the country to make it economically efficient to travel to their potential donors for visits. The potential problem that arises is that the priority for giving that major gift officers at Central Development have may not be the same priority as that of the school they are supposed to represent.

The emerging issues among organizational characteristics relate to centralization, political process, and competition. The centralization issue is the dual reporting responsibilities that some of the development officers and administrators in the small academic units have to their deans and to central development. This dual reporting situation means that these positions are either jointly or entirely funded by the central administration. This is good because it provides small units additional staff to seek funds but it runs the risk of people in those positions having divided loyalties between the professional school where they work and Central Development which pays them. The political process issue relates to the prospect coordinating system where breakdowns in coordination lead to bad feelings between professional schools or fund-raising units. It appears the system needs some fine-tuning to be sure it works without creating animosity. The emerging issue related to competition is the increasing pressure the development units are feeling as the upcoming campaign approaches its official kick-off. It is this increasing pressure that is being blamed for breakdowns in the prospect coordinating system.

One general observation from the study is that there appear to be two types of stewardship activities-those that lend themselves to standardization and those that are extremely personal. The aspects of stewardship that can easily be standardized can be described as "mechanical aspects of stewardship" and the very personal aspects of stewardship which can only be managed by individuals who have a close personal relationship with the donor can be described as the "interpersonal aspects of stewardship." Central Development has centralized many of the mechanical aspects of stewardship but the interpersonal aspects of the process must remain in the hands of the professional school development offices where the personal relationships between the staff and major donors are strongest.

\section{A Revised Conceptual Framework}

One challenge in using a conceptual framework to guide a qualitative study is trying to avoid the temptation to make the data collected fit neatly into the variables in the framework. The data collected did fit the conceptual framework, thus confirming its utility. Nonetheless, the author remained open to emerging issues and concepts which did not fit neatly into the variable categories. Some of these emerging issues were discussed in the previous section. Others are incorporated into the discussion of the revised framework.

Overall, it was not found necessary to make drastic modifications to either the conceptual framework or the explanation of the environmental and organizational dimensions and variables of the conceptual framework. The changes that were made were based on unanticipated findings and on a relative prioritization of 
the importance of certain factors to the study (see Figure 2). The basic framework has remained intact, but the overall framework has been expanded to take into account the underlying importance of four emerging issues: (1) organizational size, (2) the existence of an internal and an external institutional environment, (3) the importance of resources within the development office, and (4) changes in conditions and factors that occur over time. As noted in the emerging issues outlined in the preceding section, there is a vast disparity in resources, both financial and staffing, between the large unitsBusiness, Engineering, and Law-and the small units-Dentistry and Music. Rather than simply incorporate this finding into the task environment variables under resources, it is felt that this disparity is so important to an organization's ability to provide a formalized and fully elaborated stewardship program for its major donors that two boxes were added outside the original framework to differentiate between organizational sizes. These boxes are labeled "large units" and "small units." Resources were also addedto the conceptual dimensions under organizational factors in the development office.

Another issue that emerged from the legal coercion variable of the control dimension of the institutional environment is the existence of two separate institutional environments-one external to the organization that Oliver investigated and a second one that is internal to the organization. ${ }^{42}$ This was reinforced by the centralization variable

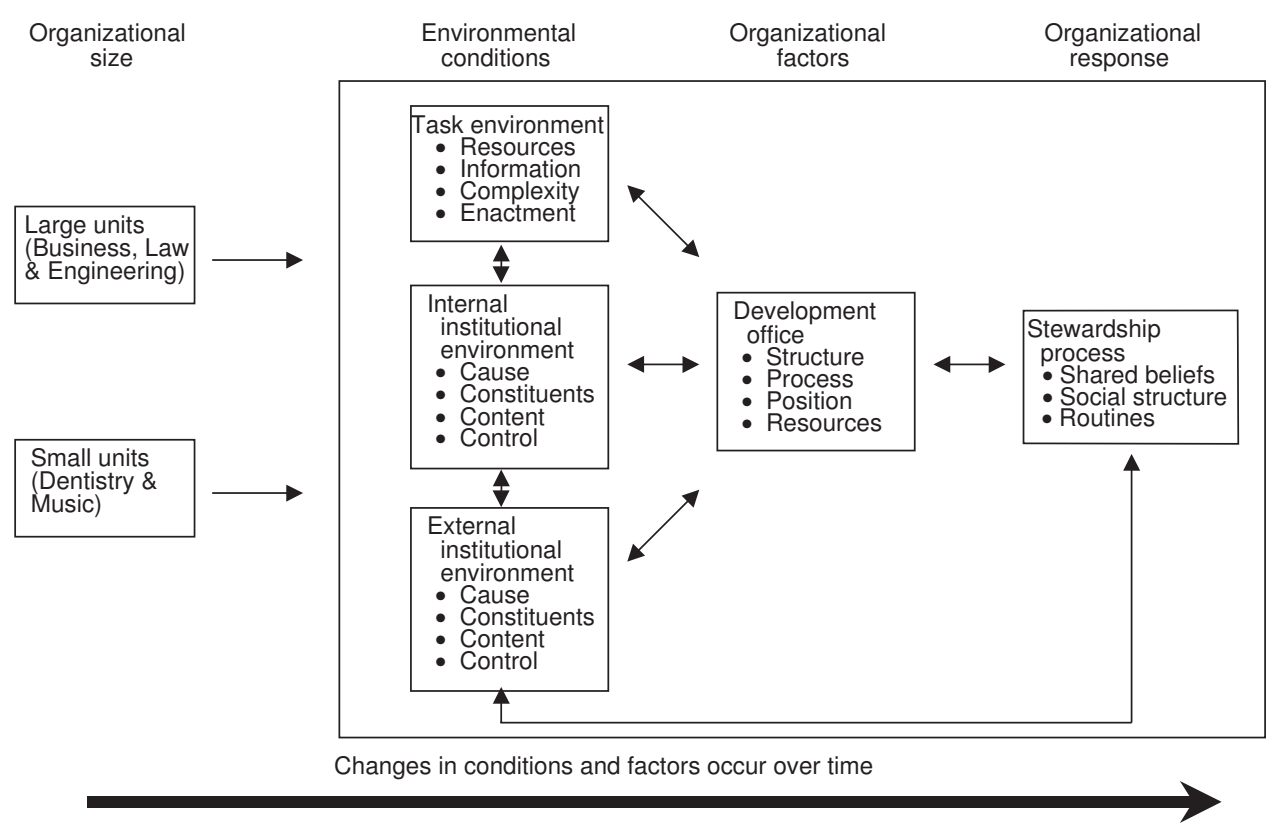

Figure 2: Conceptual framework: Revised determinants of the strategic organizational response called stewardship 
under the structure dimension of the organizational factors. To emphasize the importance of these two environments, a second institutional environment box was added with one labeled "internal institutional environment" and the other labeled "external institutional environment."

The fourth emerging issue that became increasingly important as the data were analyzed was that conditions in the task and institutional environments and factors among the organizational characteristics change dramatically over time. In the five years since the first stewardship survey at the University of Michigan, there have been a number of conditions and factors that have changed in all the units. Over the past two years, these changes have been even more dramatic. Additionally, the author has been told that the result of work currently being done in preparation for the new campaign and the work that will be done during the campaign will be manifested in additional changes to the stewardship process in the professional schools and college which were investigated. Thus a directional arrow at the bottom of the framework that is titled "changes in conditions and factors occur over time" has been added.

Beyond the changes made to the overarching conceptual framework, three variables have been added to the explanation of the environmental and organizational dimensions and variables of the conceptual framework. The first two variables were added to resources in the task environment. The variables were diversification and stockpiling.

Diversification was added because three of the more successful professional schools and the college had alternative sources of funds that supplemented the income which had been considered would be normal for organizations of their type. The Business School has its Executive Education Programs, the College of Engineering has its large infusion of research grants and contracts, and the School of Dentistry has income from its dental clinics to supplement their "normal" revenue streams. Thus, diversification has been defined as the extent to which the organization has alternative external sources of revenue. ${ }^{43}$

The stockpiling variable has also been added to resources because in reviewing the operating budgets of the four professional schools and one college it became increasingly apparent how important endowments were to these organizations' budgets. In some cases, endowment income vastly exceeded the expendable income generated by annual and unrestricted fund-raising efforts. In any event, endowment was deemed critical to the case study organizations' ability to provide financial aid to their students and to staff to their development offices. Thus, stockpiling is defined as the extent to which the organization sets aside critical slack resources to buffer against uncertainties in the future. ${ }^{44}$

The last additional variable was intraorganizational coercion to the control condition of the institutional environment. This was added because the author did not believe that the variables, identified under Oliver's control dimension, adequately accounted for the coercion which emanates from a superior organization within the university-wide organizational hierarchy. Intraorganizational coercion is defined here as the extent to which the focal organization is being coerced to conform 
by another organization above it in the larger university hierarchy. ${ }^{45}$

\section{Implications for Theory}

This study contributes to organizational theory in four distinct domains: task environments, institutional environments, organizational factors, and organizational responses. Task environments determine what an organization within a complex university setting must do in order to survive. The four environmental conditions identified in the conceptual framework appear to adequately describe the task environment. Resources determine how an organization will relate itself to its external environment for its primary technology-how dependent it is on external actors for its existence and how available resources are to enable it to achieve its organizational goals. This study identified two additional resource-based variables that influence what the organizations do to adapt themselves for survival. These variables are diversification and stockpiling. By diversifying, an organization can generate additional sources of revenue outside its primary technology or within its primary technology but outside the university context. By stockpiling, an organization can buffer its financial position by setting aside critical slack resources for future uncertainties. ${ }^{46}$

Viewing institutional environments narrowly highlighted some deficiencies in Oliver's antecedents of organizational responses. ${ }^{47}$ The main deficiency is within the control condition in which legal coercion and voluntary diffusion of norms external to the organization were not broad enough to account for all the pressures to conform that are imposed on organizations. The addition of a separate box in the conceptual framework to designate two distinct institutional environments (one internal to the organization and one external to it) plus the addition of the intraorganizational coercion variable (in which an organization is pressured to conform by another organization above it in a larger university hierarchy) seems to more completely explain this condition.

All of the organizational factors identified in the conceptual framework appeared to adequately bound the parameters of the stewardship process. However, interdependence between an organization and its major donors only fully emerged in the School of Dentistry through its continuing dental education program. Overall, stewardship appears to be an organizational response to the influences of the task and institutional environments and the organization's characteristics.

\section{Implications for Practice}

Much of what is found in the individual case studies is what practitioners would expect to find in a study of stewardship. The implications that are important for practitioners to understand are the emerging issues that have been identified. First is the new culture of philanthropy in which younger donors are now capable of making significant gifts to colleges and universities. Practitioners will need to develop new compelling case statements that will appeal to a younger generation of philanthropists. Second is the finding of such a wide discrepancy in the ability of large and small units to provide fully elaborated programs of stewardship for their major donors. University development administrators will need to identify ways of supporting the smaller 
development operations so that stewardship for major donors is consistent and effective across the whole range of development organizations.

The third issue for practitioners is the need to listen to their major donors when they make suggestions about successful fund-raising practices. It is especially important to listen to those who have affiliations with other institutions or organizations that are successful in fund raising. Not only do these donors want their professional school to be successful, but they are often quite knowledgeable about philanthropic issues. They expect high standards of professionalism and high levels of performance from the organizations they support.

The fourth issue for practitioners is the problem of dual reporting responsibilities of development officers in the units-both to the dean of the school and to an executive in central development administration. Though this may not present a problem, the perception may still exist that loyalties are divided by such an arrangement. Administrators will need to find ways to diminish this perception.

The fifth issue for practitioners is the development officers in a central office who make calls on donors and prospects for smaller units in geographic areas in which it is not economically feasible for the small units to make calls. This, too, risks the perception of divided loyalties or of different priorities between the central development officer and the school. Administrators will need to find ways to address these potential conflicts.

A sixth issue is breakdowns in the prospect coordinating system. Conflicts can arise from development officers making calls on donors who have multiple affiliations to a college or university especially as a campaign approaches. Special attention will need to be paid to ensuring that coordination is effective and that breaches of protocol are addressed quickly and effectively.

A seventh issue arises from the "mechanical versus interpersonal" aspects of stewardship. Central Development at the University of Michigan has done a good job of centralizing the mechanical aspects of stewardship while allowing the units to concentrate on the interpersonal aspects of the process. Because Central Development has been successful at this without raising fears that it is centralizing the entire stewardship process, the university may want to represent itself as a model for other universities that need to have more consistent gift acknowledgements, gift records, development research, gift recognition programs, and other stewardship processes that are appropriate for standardization.

\section{Suggestions for Future Research}

This study has been fairly comprehensive in viewing the stewardship process in terms of task environments and organizational characteristics. A second look at the institutional environment for stewardship, one using a more integrated approach to the conceptual framework, would, however, be beneficial. Oliver's antecedents are a good starting point, but a broader view of institutional theory would be a valuable addition to the body of fund-raising knowledge. ${ }^{48}$

This study should also be replicated in other college and university contexts-both organizations with complex development structures like those at the University of Michigan and in other development contexts including universities in which "successful" stewardship programs are in 
place. Studies such as these would perhaps help verify the generalizability of the results of this study of stewardship to other contexts.

Another valuable addition to this scholarship would be to incorporate the voices of major donors into it in some way. Even if one-on-one interviews are not possible, it would be beneficial to understand major donor opinions as to what they believe constitutes appropriate stewardship. This would provide a more complete picture of the stewardship process from all perspectives.

Finally, it would be good to address the stewardship process from a more micro perspective by developing studies to investigate agency or boundary spanning theories in relation to the stewardship process.

\section{Closing Thoughts}

One closing thought relates to access issues. Stewardship is a very sensitive issue in the development process, especially in an organization where stewardship is just developing and is uneven in how it is provided to major donors across academic units. Gaining access to major donors, which is what is needed to gain a complete picture of the stewardship process at the University of Michigan (UM), is not something that will be readily available to researchers either at UM or at other colleges and universities across the country. Relationships between institutions and their major donors are too sensitive to risk the downside potential of losing even one donor to the bad feelings that may arise from an illtimed or ill-advised question. One of the development staff members with whom these issues were discussed was even nervous about interviewing deans because of the potential risk to development administrators of bringing a poor job of stewardship to the attention of a dean.

Finally, a closing note about the cost of not doing good job stewardship: during a conversation with a high ranking development administrator at Central Development and two unit development officers, they all agreed that it would be very hard to tell definitively whether a stewardship process is effective or not. However, they uniformly agreed that the cost of not doing stewardship effectively was so high that it is imperative to do it right. Their reasoning was that the time and energy it takes to bring a major donor back into the fold once he or she is alienated is so great and the relationships salvaged so few that it is essential to provide good stewardship for every major donor.

\section{References}

1. W. B. Cook and W. F. Lasher (1996), "Toward a theory of fund raising in higher education," Review of Higher Education, 20, 1, pp. 33-51; K. S. Kelly (1998), Effective Fund-Raising Management, Lawrence Erlbaum Associates, Mahwah, NJ.

2. N. C. Gross, W. S. Mason, and A. W. McEachern (1958), Explorations in Role Analysis, Wiley, New York; K. Langfield-Smith, K. (1992), "Exploring the need for a shared cognitive map," Journal of Management Studies, 29, 3, pp. 349-68; R. R. Nelson and S. G. Winter (1982), An Evolutionary Theory of Economic Change, The Belknap Press of Harvard University Press, Cambridge, MA; L. S. Sproull (1981), "Beliefs in organizations," in P. C. Nystrom and W. H. Starbuck (Eds.), Handbook of Organizational Design, Vol. 2, Oxford University Press, Oxford.

3. W. R. Scott (1998), Organizations: Rational, Natural, and Open Systems, 4th edn, Prentice-Hall, Englewood Cliffs, NJ, pp. 133-34.

4. Ibid, p. 131.

5. T. G. Barrett (2002), "Stewardship as an organizational response: Understanding the interaction of institutional and task environments and organizational contexts on fund raising in professional schools and colleges," Unpublished doctoral dissertation, University of Michigan, Ann Arbor. 
6. W. R. Scott (1995), Institutions and Organizations. Sage, Thousand Oaks, CA.

7. M. D. Cohen and P. Bacdayan (1994), "Organizational routines are stored as procedural memory: Evidence from a laboratory study," Organization Science, 5, 4, pp. 554-68.

8. Langfield-Smith, K (1992), "Exploring the need for a shared cognitive map," op. cit.

9. Scott (1998), Organizations, op. cit., p. 17.

10. Gross et al. (1958), Explorations in Role Analysis, op. cit.

11. Nelson and Winter (1982), An Evolutionary Theory of Economic Change, op. cit., p. 14.

12. Ibid, p. 17.

13. J. R. Blau, R. McVeigh, and K. C. Land (1994), "The expansion of two-year colleges: Tests of institutional and political economy theories in a dynamic model" (ERIC Document Reproduction Service No. ED368399); P. S. Tolbert (1985), "Institutional environments and resource dependence: Sources of administrative structure in institutions of higher education," Administrative Science Quarterly, 30, pp. 113; C. Oliver (1991), "Strategic responses to institutional processes," Academy of Management Review,16, 1, pp. 145-79; Scott (1998), Organizations, op. cit.

14. Scott (1998), Organizations, op. cit.

15. Scott, W. R. (1995), Institutions and Organizations, op. cit.

16. J. Pfeffer and G. R. Salancik (1978), The External Control of Organizations: A Resource Dependence Perspective, Harper \& Row, New York.

17. P. R. Lawrence and J. W. Lorsch (1967), Organization and Environment: Managing Differentiation and Integration, Graduate School of Business Administration, Harvard University, Boston, MA; J. D. Thompson (1967), Organizations in Action, McGraw-Hill, New York.

18. Lawrence and Lorsch (1967), Organization and Environment, op. cit.; Thompson (1967), Organizations in Action, op. cit.

19. K. R. Weick (1979), The Social Psychology of Organizing, 2nd edn McGraw-Hill, New York.

20. C. Oliver (1991), "Strategic responses to institutional processes," Academy of Management Review, 16, 1, pp. 145-79.

21. Ibid

22. R. H. Miles (1980), Macro Organizational Behavior, Goodyear, Santa Monica, CA.

23. D. M. Carchidi (1999), "The virtual delivery and virtual organization of postsecondary education," Unpublished doctoral dissertation, University of Michigan.

24. Scott (1998), Organizations, op. cit.; G. C. Homans (1950), The Human Group, Harcourt, New York;
Pfeffer and Salancik (1978), The External Control of Organizations, op. cit.

25. S. G. Rosevear (1999), "Understanding the formation of a cross-industry alliance in the knowledge industry," Unpublished doctoral dissertation, University of Michigan.

26. Scott (1998), Organizations, op. cit.

27. Oliver (1991), "Strategic responses to institutional processes," op. cit.

28. Cook and Lasher (1996), "Toward a theory of fund raising in higher education," op. cit.

29. R. K. Yin (1994), Case Study Research: Design and Methods, 2nd edn, Applied Social Research Methods Series, Vol. 5, Sage, Thousand Oaks, CA.

30. K. R. Weick (1988), "Enacted sensemaking in crisis situations," Journal of Management Studies, 25, pp. 305-17.

31. Oliver (1991), "Strategic responses to institutional processes," op. cit.

32. Ibid.

33. Ibid.

34. Ibid.

35. Miles (1980), Macro Organizational Behavior, op. cit.

36. Ibid.

37. Ibid.

38. Ibid.

39. Scott (1998), Organizations, op. cit.

40. Homans (1950), The Human Group, op. cit.

41. Pfeffer and Salancik (1978), The External Control of Organizations, op. cit., p. 49.

42. Oliver (1991), "Strategic responses to institutional processes," op. cit.

43. Scott (1998), Organizations, op. cit.

44. Ibid.

45. Oliver (1991), "Strategic responses to institutional processes," op. cit.

46. Scott (1998), Organizations, op. cit.

47. Oliver (1991), "Strategic responses to institutional processes," op. cit.

48. Ibid.

\section{Acknowledgements}

This paper, based on the author's doctoral dissertation, was presented in an earlier version at the 42nd Annual Forum of the Association for Institutional Research in Toronto, Canada, June 2002. He wishes to express his appreciation to Marvin W. Peterson, Chair, Eric L. Dey, and Jane E. 
Dutton of the University of Michigan, and Donald E. Heller of the Pennsylvania State University for their patience, guidance and supervision of the dissertation research that made this article possible.

\section{Practitioner's Perspective}

Much of the research and literature on fund raising as a process focuses on attracting new donors. Writings and workshops abound on best practices for acquiring first-time donors. Barrett's article on stewardship builds upon the body of knowledge regarding the equally important function of retaining these hardfought-for donors through a heightened contextual awareness of stewardship practices.

A fund-raising practitioner in today's highly competitive market seeks every advantage to ensure that donors feel connected and valued. Through this article, the practitioner views stewardship as an integral process within the fund-raising cycle that is shaped by the environment and organizational culture in which it operates. Barrett effectively builds upon a framework that outlines primary variables affecting stewardship programs. A number of pragmatic applications may be drawn from the findings and conclusions in Barrett's research.

First, development managers charged with the oversight of large decentralized operations may gain perspective by reconsidering the unique nature of the colleges and schools under their management. Each academic area has its own lexicon, opportunities to engage its publics, and range of resources that should be weighed carefully in designing an effective stewardship program. While some economies of scale may be achieved through centralized stewardship activities, not all functions may reach optimal performance with a one-size-fits-all approach.

Certain stewardship activities are mechanical and may be standardized (such as thank-you letters, gift acknowledgements, and annual endowment reports); however, the interpersonal connection between a donor and the individual closest to the area the donor supports-often in a decentralized unit-should remain paramount.

Second, a donor-centered approach is essential to all stages of the relationshipbuilding cycle beginning with a compelling case statement and sound strategy tailored to each segment of a donor population. That same focus should guide the development of sound stewardship planning that integrates individualized donor interaction with centralized processes. Successful development officers listen intently to their donors, especially to those who support multiple charitable interests, and measure each organization to the standard of donor relations they consider the best.

Third, performance standards and measurements for stewardship staff should be set as rigorously as goals and objectives are set for front-line fund raisers. Inherent in this process is a fundamental call to first recruit, and then retain, the best people. Barrett's research revealed that in the Michigan study the most successful 
operations recruited staff who had demonstrated prior success in other areas of the University's fund-raising program rather than recruiting from off campus.

Fourth, the dual reporting association for development officers with stewardship oversight in a decentralized operation adds complexity for central development managers. Both the political process and competitive aspect of prospect management systems produce constraints which must be addressed if donors are to be recognized in a consistent manner that reflects an overall institutional commitment to its benefactors.

Fifth, the dynamic nature of the environment and organizational culture in which fund raising operates demands periodic self-evaluation. In fact, each of the colleges and schools examined in the Michigan study increased the priority and emphasis of stewardship in their respective areas based on conclusions drawn from regular self-evaluation.

The quantifiable side of development, often measured by dollars raised and new donors acquired, is an essential representation of fund-raising success. Astute development practitioners, however, will keep an equally vigilant eye on an outcome that is less quantifiable: donor loyalty. Retaining our most valued donors through stewardship practices that resonate with each donor will strengthen loyalty and position the donor for future giving. 